\title{
EDUCAÇÃO, PANDEMIA E O PROJETO “REFÓRSSUS"
}

\section{José Fernando Ebling Rosauro'; Bruna Camargo²; Deividi Fernando Borges da Cunha $^{3}$; Jussara Macali ${ }^{4}$; Kathiusca de Fátima Neto Rodrigues ${ }^{5}$; Kátia Fogaça Martins $^{6}$; Leticia Oberoffer Stefenon ${ }^{7}$}

\section{RESUMO}

Este trabalho tem por objetivo apresentar o Projeto "Refórssus", que assomou ao enfrentamento das dificuldades impostas pela Pandemia do Coronavírus, pois a educação foi uma das áreas mais afetadas. No entanto foram necessárias grandes adaptações da modalidade de ensino presencial para a remota. Após notados os altos índices de evasão escolar, desigualdades educacionais e a brusca adaptação para com as tecnologias, surgiu o Projeto "Refórssus". Dessa forma em sua metodologia traz um pouco das tecnologias educacionais e seu objetivo principal é contribuir para a redução dos índices de evasão escolar, desigualdades educacionais e superação das incompreensões tecnológicas. $\mathrm{O}$ artigo foi desenvolvido de forma descritiva por um grupo de acadêmicos da UFN (Universidade Franciscana) da cidade de Santa Maria, RS.

Palavras-chave: Educação; Tecnologia; Evasão escolar.

Eixo Temático: Educação, Cultura e Comunicação (ECC).

\section{INTRODUÇÃO}

É de grande notoriedade que a pandemia da Covid-19 impactou outras áreas além, da saúde. A educação pública de nível fundamental e médio foi consideravelmente uma das áreas que mais martirizou-se com a pandemia. Para isso, foram necessárias grandes adaptações das aulas presenciais para as remotas.

A falta de equipamentos tecnológicos e a incompreensão das tecnologias foram grandes auxiliadores para conturbar esse momento. Além disso, podemos ressaltar

\footnotetext{
${ }^{1}$ Acadêmico do curso de Matemática - UFN - j.rosauro@ufn.edu.br.

${ }^{2}$ Acadêmica do curso de Letras Português e Inglês - UFN - camargo.bruna@ufn.edu.br

${ }^{3}$ Acadêmico do curso de Pedagogia - UFN - deividi.fernando@ufn.edu.br

${ }^{4}$ Acadêmica do curso de Pedagogia - UFN - jussara.m@ufn.edu.br

${ }^{5}$ Acadêmica do curso de Pedagogia - UFN - K.neto@ufn.edu.br

${ }^{6}$ Orientadora. Professora da rede estadual do Rio Grande do Sul - katiafogacamartins@gmail.com

${ }^{7}$ Orientadora. Professora do curso de Matemática - UFN - leticia.stefenon@ufn.edu.br
} 
que a falta de recursos oriundos do poder público aflige ainda mais a educação, causando uma desigualdade educacional expressiva entre os educandos e educadores. Nesse ínterim a evasão escolar também obteve bastante presença nas pautas sobre educação, acarretando grande freima por parte dos professores.

\subsection{EDUCAÇÃO E TECNOLOGIA}

Constatamos que muitos professores tiveram grandes dificuldades em aderir as tecnologias educacionais. Dessa forma, podemos perceber que a probabilidade de evasão escolar concentrou um número bastante expressivo, tornando-se uma das maiores preocupações por parte dos educadores. A falta de equipamentos tecnológicos para a educação foi um fator que gerou muitas desigualdades tanto entre escolas quanto alunos e professores. Cabe ainda externar que a carência na formação em informática básica tornou o momento muito mais deplorável.

Obtendo menção na reportagem da UFMS (Fundação Universidade Federal de Mato Grosso do Sul) sobre tecnologias educacionais, onde ressalta Hélio Queiroz Daher (2020), há relatos de alunos que auxiliaram os professores com as ferramentas tecnológicas, sendo assim grandes auxiliadores do período pandêmico na educação e contemplando diversas escolas públicas. Desse modo podemos dizer que esse período auxiliou para a quebra de muitos tabus, como por exemplo, o uso do celular em sala de aula, bem como é citado na reportagem da UFMS de Paula Pimenta: "[...] educação secular não vai existir mais. Não há mais como proibir, por exemplo, o uso do celular em sala de aula. [...]" (LEONEL, 2020). As tecnologias inseriram-se de maneira à auxiliar na educação e na didática desenvolvida pelos professores em sala de aula. Desse modo acredita-se que além de materiais já usados, após a pandemia, terá a inserção de objetos tecnológicos em salas de aulas, podemos citar a cidade de São Pedro Do Sul, RS que equipou as escolas municipais com equipamentos tecnológicos tais como, Tvs, Chromebooks e potencialização da internet.

\subsubsection{Surgimento do Projeto "Refórssus"}

O Projeto "Refórssus" assomou para auxiliar no combate às dificuldades enfrentadas pelos alunos por estarem divididos entre o retorno presencial e o ensino 
remoto. Por meio do PIBID (Projeto Institucional de Bolsa de Iniciação à Docência) observou-se necessidade dos alunos, que optaram pelo ensino remoto, ter acesso a uma explicação adequada de seus respectivos conteúdos, por meio de aulas de reforço. Ainda, que o projeto objetiva combater a evasão escolar, as desigualdades educacionais e a incompreensão tecnológica, acompanhando o desenvolvimento do aluno. Justifica-se:

a) Evasão escolar: A dificuldade em obter acesso aos conteúdos, nas disciplinas, também a necessidade de os jovens auxiliar na complementação da renda familiar e a falta de políticas sociais para a área educacional perscruta para o desencadeamento da evasão escolar, como citado na reportagem acadêmica da UFRGS (Universidade Federal do Rio Grande do Sul) em Jornal da Universidade:

"As políticas andam juntas, no sentido de que não é só uma questão de educação, mas de políticas sociais mais amplas. Se tivermos políticas sociais que possibilitem que as famílias desses jovens tenham melhores condições de vida, facilita que os jovens permaneçam na escola." (LIMA, 2021).

O número de matriculados nas escolas do Rio Grande do Sul em 2020 (período de início da pandemia do coronavírus) caiu cerca de 374 mil isso equivale a 93,7\%. Esses dados são referentes à adolescente entre 15 e 17 anos, esses dados também são referências da reportagem acadêmica da UFRGS.

b) Desigualdade educacional: A localização das escolas e a situação financeira da comunidade escolar amplifica as desigualdades educacionais. Ainda assim, estudantes de escolas públicas deparar-se-ão com mais obstáculos a aqueles que estudam em escolas privadas. A referida situação pode ser justificada através de uma entrevista do Jornal Nacional onde, o entrevistado lamenta-se:

"Os alunos das escolas privadas estão estudando 3 horas e 6 horas que não era 0 que deveriam, mas é mais de 1 hora do que os alunos pobres. É uma consequência bastante preocupante, porque com todos os pesares sociais, as mazelas que o Brasil já tinha e vinha piorando no período de crise pré-pandemia, uma coisa melhorava como um vento que soprava a favor que era a redução da desigualdade de educação, os pobres conseguiam fechar o gap educacional ao longo do tempo. Com a pandemia, isso foi revertido, o vento a favor começa a soprar contra. Eo problema da educação deixa marcas" (NERI, 2021). 
c) Incompreensão tecnológica: A falta de investimentos nas formações em informática básica, vem acarretar a incompreensão tecnológica. Como citado anteriormente, no decorrer desse artigo onde destaca a situação de que alunos auxiliaram seus professores a compreenderem a expansão tecnológica da educação. Uma pesquisa realizada com diversos professores da rede pública de ensino referente ao uso das tecnologias e logo após apresentado por um canal de notícias enfatiza: "89\% não tinha experiência anterior à pandemia para dar aulas remotas-e 42\% dos entrevistados afirmam que seguem sem treinamento, aprendendo tudo por conta própria. Para 21\%, é difícil ou muito difícil lidar com tecnologias digitais.” (G1, 2020).

\subsubsection{Projeto "Refórssus" na prática}

O Projeto "Refórssus", aplica-se em uma turma de oitavo ano, em uma escola Estadual, da cidade de Santa Maria, RS. Considerando a necessidade dos educandos, o projeto distribuiu-se da seguinte forma:

a) Solicitação de desenvolvimento: Como o projeto é desenvolvido dentro de um Programa Institucional, PIBID, foi solicitado à coordenação do mesmo, logo então aprovado como um projeto de aulas de reforço de matemática.

b) Aceitação dos alunos: Tendo a aprovação da coordenação do PIBID, foi realizado o comunicado aos alunos que optaram pelo ensino remoto, havendo aceitação unânime.

c) Primeiro encontro remoto com alunos: No primeiro encontro com os alunos optantes do ensino remoto, foi introduzido o objetivo e em seguida realizado uma aula expositiva e interativa com eles. O conteúdo foi definido junto da professora regente onde obedece ao programa institucional da disciplina de matemática, de acordo com a BNCC (Base Nacional Comum Curricular).

\section{METODOLOGIA}

Para a realização deste trabalho a metodologia de estudo foi descritiva. Integrado pelos estudantes de Matemática, Letras Português e Inglês e Pedagogia da Universidade Franciscana de Santa Maria, Rio Grande do Sul, realizada no mês de setembro do ano de 2021. Para o desenvolvimento do projeto foram desenvolvidas 
apresentações de slides, exercícios de fixação, reprodução de música, jogo educacional baseado no conteúdo e os encontros foram realizados pela plataforma Google Meet.

\section{RESULTADOS E DISCUSSÕES}

Após estudos referentes a educação em tempos de pandemia, tivemos a noção de que a momento pandêmico abalou muito a atualidade. A educação vivenciou um alto índice de evasão escolar, o que muitas vezes foi ocasionado pela dificuldade de acesso a nova maneira de aprender, e nota-se que a evasão escolar se fez presente principalmente onde a classe social era mais precarizada. Além do mais, a incompreensão das tecnologias educacionais afetou alguns alunos além de professores, excedendo aqueles que supostamente possuíam mais recursos financeiros para a aquisição. É bastante perceptível que a falta de políticas sociais se aliando da pandemia do Covid-19 deplorou muito a situação de alunos, professores e escolas com baixa renda. Dessa forma, podemos dizer que o Projeto "Refórssus", juntou-se ao combate das desigualdades educacionais, permitindo que alunos sem acesso as escolas pudessem aderir uma explicação benévola do conteúdo.

\section{CONCLUSÃO}

A importância em possuir uma educação de qualidade foi explicitada no decorrer deste trabalho, sendo uma das principais questões a ser defendida no atual cenário pandêmico, quando se tem políticas sociais, podemos notar que a evolução da educação é muito mais visível, pois elimina a visão da educação secular, ou seja, remete a uma nova forma de ver as situações educacionais. No entanto, não foram todas as instituições de ensino que tiveram condições de acompanhar a expansão das tecnologias o que gera as chamadas incompreensões tecnológicas.

Portanto, fica evidente, quando são desenvolvidos projetos que podem ser motivacionais aos alunos, a educação apresenta uma nova aparência, pois nos últimos anos a educação foi considerada monótona, sem atividades que pudessem diversificá-la. O Projeto "Refórssus" é a uma das provas de que a educação dispõe de vários aspectos para se reinventar, e é uma das súperas maneiras para se cativar um 
estudante. Dessa forma observa-se na aplicação do projeto que o empenho dos alunos superou as expectativas, desencadeando facilidade na maioria das aulas quais foram acompanhados.

\section{AGRADECIMENTOS}

Externo meus agradecimentos ao PIBID (Projeto Institucional de Bolsa de Iniciação à Docência) dentre o subprojeto Pedagogia-Matemática e sua respectiva coordenação: Eliane Galvão, Greice Scremin, Letícia Fogaça e Leticia Stefenon, pois contribuiu para o desenvolvimento do Projeto "Refórssus". Agradeço a professora Kátia Fogaça Martins, supervisora local do PIBID e professora regente da turma de aplicação do projeto. A Secretaria Municipal de Educação de São Pedro do Sul, pela experiência que obtive no período em que fiz parte da equipe e pela autorização da citação no investimento em ferramentas de tecnologias educacionais. Ao acadêmico Pedro Ângelo Miri (Licenciatura em Filosofia - Universidade Franciscana), que contribuiu como supervisor de texto. E aos escritores deste artigo.

\section{REFERÊNCIAS}

DAHER, H. Q.; LEONEL, W. Discussões sobre Educação em tempo de pandemia mostram inquietudes e desafios do presente-futuro. Mato Grosso do Sul, ago. 2020. Disponível em: https://www.ufms.br/discussoes-sobre-educacao-emtempo-de-pandemia-mostram-inquietudes-e-desafios-do-presente-futuro/. Acessado em: 19 set. 2021.

LIMA, I. G. de. Desempenho do RS foi pior do que a média brasileira em mais da metade dos índices da educação básica em 2020. Rio Grande do Sul, março 2021. Disponível em: https://www.ufrgs.br/jornal/desempenho-do-rs-foi-piordo-que-a-media-brasileira-em-mais-da-metade-dos-indices-da-educacao-basica-em2020/. Acessado em: 19 set. 2021.

NERI, M. Pandemia aprofunda ainda mais a desigualdade entre os brasileiros em relação à educação. Rio de Janeiro. Fev. 2021. Disponível em: 


\section{QUFN}

https://g1.globo.com/jornal-nacional/noticia/2021/02/08/pandemia-aprofunda-ainda-adesigualdade-entre-os-brasileiros-em-relacao-a-educacao.ghtml. Acessado em 20 set. 2021

G1. Quase $90 \%$ dos professores não tinham experiência com aulas remotas antes da pandemia; $42 \%$ seguem sem treinamento, aponta pesquisa. São Paulo. Jul. 2020.

Disponível em: https://g1.globo.com/educacao/noticia/2020/07/08/quase-90percent-dos-professoresnao-tinham-experiencia-com-aulas-remotas-antes-da-pandemia-42percent-seguemsem-treinamento-aponta-pesquisa.ghtml . Acessado em: 20 set. 2021. 